\title{
Arctic Meteorology*
}

By DR. G. C. Simpson, c.B., C.B.E., F.R.S.

$\mathrm{I}^{\mathrm{N}}$ 1905 appeared Mohn's discussion of the meteorological records obtained during Nansen's drift across the north polar basin on board the Fram during the three years October 1893August 1896. No one who is interested in polar meteorology needs to be reminded of the outstanding value of that great work, which has been for thirty years the source of practically all we know about the atmosphere over the Arctic Ocean.

Now has appeared another great contribution to our knowledge of arctic meteorology, again obtained on the drift of a Norwegian ship and discussed by another outstanding Norwegian man of science. When Mohn's work appeared, the name Fram was a household word to the whole civilised world; but how many people even in England know anything about the Maud? Yet the Maud's sojourn in the Arctic, where she was engaged on the same enterprise of scientific research, was even longer than that of the Fram, and her scientific results no less valuable.

Amundsen's successful dash to the South Pole was a mere episode in a project on which he had been working for several years : namely, to repeat Nansen's drift across the Arctic Ocean in the Fram. In fact, he was on his way from Norway to the Bering Straits around Cape Horn when he changed his plans at Madeira and went to the Antarctic. On his return to Norway he proceeded with his original plans; but the old Fram was found to be nearing the end of a glorious life and was no longer fitted for such strenuous work. Then the War broke out, but Amundsen did not relinquish his plans. In 1916 he gave orders for a new ship to be built, on the lines of the Fram, but smaller ; on June 7, 1917, the new ship was launched and christened Maud.

On July 18, 1918, the Maud left Vardø, with Amundsen in charge, the total ship's party being only nine men. The plan was to sail eastwards along the Siberian coast towards the Bering Straits and then turn northwards into the ice and drift with the pack across the Pole. That was the plan, but it did not eventuate: for seven years the Maud remained in the Arctic the greater part of the time, either frozen fast near the coast or drifting aimlessly to the east of the New Siberian Islands.

Luckily for him, and more so for science, Amundsen in 1917 invited H. U. Sverdrup, a

* The Norwegian North Polar Expedition with the Maud, 1918-1925. Scientific Results. Vol. II. Meteorology. By H. U. Sverdrup. (Geofysisk Institutt, Bergen, in co-operation with other Institutions.) young Norwegian who had never been in the Arctic before, to take charge of the scientific work of his expedition. Sverdrup consented and was one of the two men who alone saw the expedition through, starting with the Maud at Vardø in 1918 and leaving her when she returned to Nome in August 1925.

During the first three years, Sverdrup was the only trained scientific worker on board-Amundsen helped with the magnetic work but he was disabled for a long period with a broken arm-but in 1922 F. Malmgren, whose tragic death after the disaster to Nobile's airship in 1928 will be fresh in the memory of most, joined the expedition as assistant scientist. In these circumstances the amount of scientific work carried out on the expedition is amazing. Observations of the first importance on oceanography, terrestrial magnetism, atmosphere electricity and meteorology were carried out; zoological, botanical and geological collections were made, and Sverdrup spent seven and a half months living with a littleknown group of native nomads in order to study their language and customs, and characteristically enough during the whole time he was with them he made meteorological and magnetic observations.

The volume on meteorology which has just been published consists of two parts: Part II (527 pages) contains all the data in 28 well-arranged tables, and Part $I$ is a discussion running to 331 pages written by Sverdrup himself. Naturally one compares Sverdrup's discussion of the results of the Maud expedition with Mohn's discussion of the Fram results. There is one striking difference : Mohn's discussion is limited almost entirely to working up the statistics of the observations, while the outstanding feature of Sverdrup's treatment is his investigation of the physics and dynamics underlying the observations. The difference is symptomatic of the great advance made by meteorology in the interval. Thirty years ago meteorological observations, even in settled countries, consisted of little more than observations of pressure, wind, temperature, cloud . and precipitation all made at the surface, and the meteorologist could do little more than find statistical relationships between them. Such were the observations carried out on the Fram, and Mohn's discussion was necessarily statistical. On the Maud similar observations were made, and Sverdrup has treated them in the same way and quite as thoroughly as Mohn treated the Fram results; so that the two sources of information 
support and supplement one another. In the Maud, however, many other observations were made, and it is Sverdrup's complete and able discussion of the light which these new observations throw on old meteorological problems which makes his discussion so interesting and valuable.

For the first time we have a mass of observations from the upper air in the Arctic obtained by sounding balloons, pilot balloons and kites. The observations of the upper air temperature made by balloons and kites, of which there were 162 ascents, reveal an unexpected and important distribution of temperature over the ice. The few previous measurements of upper air temperature made over ice in polar regions had led us to expect a marked temperature inversion near the snow-covered ground during the winter. In other words, that there was a 'cold layer' of air near the surface,

It was supposed that this layer was easily removed by the wind. The observations made on the Maud show, however, that this is not the case. All that the wind does is to stir up the layers quite near to the ground. In this stirred-up layer, as one would expect, temperature decreases with height, but above it the strong inversion remains and the normal fall of temperature with height does not set in, in any season, much below 1,000 metres. There are, therefore, three definite layers of air over the Arctic sea ice, (a) a layer, $150 \mathrm{~m}$. thick in the winter, increasing to $500 \mathrm{~m}$. thick in the summer, in which the temperature decreases slightly with height, $(b)$ a layer in which there is a strong inversion, the top of which varies in height above the surface from $280 \mathrm{~m}$. in the winter to $600 \mathrm{~m}$. in the summer, (c) a layer probably reaching to the tropopause in which the temperature decreases with height in the normal way. The pilot balloon observations, of which there were 621 , gave very complete information regarding the variation of wind velocity and wind direction with height.

The peculiar distribution of temperature and the observed variations of wind with height over the ice can only be caused by eddy motion set up in the lower layers of the air, and Sverdrup uses the results of his observations to test the various formulæ put forward by Richardson, Schmidt, Köhler and Hesselberg in their theoretical work on the eddies in the atmosphere. Sverdrup's discussion is a valuable contribution to a difficult subject, and the numerical values he obtains will be found of use in a number of problems.

The diurnal variation of temperature in polar regions has been the subject of much discussion since the writer pointed out in his discussion of the meteorological observations made on Capt. Scott's Antarctic expedition that there are two types of daily variation, in one of which the maximum amplitude occurs in a spring month and in the other in a summer month. The observations taken on the Fram showed a rapid increase in the amplitude after the return of the sun until April, after which it decreased to very low values in the summer months; while in McMurdo Sound the amplitude increased steadily from the appearance of the sun until the summer and then decreased again as the altitude of the sun decreased. The observations on the Maud showed the same type as observed on the Fram, and Sverdrup gives a new explanation. It has already been mentioned that the lowest layer of the atmosphere in which the eddies cause the temperature to decrease with height thickens from the winter to the summer. Sverdrup considers that the layer is warmed up by contact with the ground and, therefore, as it gets thicker it takes more and more heat from the surface. After the sun returns, the daily temperature range tends to increase as the altitude of the sun increases; but the thickness of the layer also increases and that tends to reduce the range. The actual course is due to the relative efficacy of the two factors, the solar effect being the stronger until about April and then the eddy effect predominates.

During the last three years, after Malmgren had joined the expedition, an increased number of observations became possible, and amongst these were measurements of the incoming solar radiation, the long wave radiation received from the sky, the temperature of the actual surface of the snow and the temperature of the ice at three depths below the surface. These data supply all the information necessary to calculate the flow of heat during calm weather to and from the surface, and one of the most interesting chapters in Sverdrup's discussion is that in which he uses the results of these observations to investigate the heat balance of the atmosphere over icecovered surfaces. He calculates that the average minimum temperature on clear calm days in the winter should be $-38 \cdot 8^{\circ} \mathrm{C}$. ; the observations give $-38.9^{\circ} \mathrm{C}$. According to the calculations, the absolute minimum temperature over the frozen polar sea should lie between $-43.9^{\circ} \mathrm{C}$. and $-49 \cdot 5^{\circ} \mathrm{C}$.; the actual observations taken on the Maud in four winters give values varying between $-41 \cdot 7^{\circ} \mathrm{C}$. and $-46 \cdot 3^{\circ} \mathrm{C}$. The lowest possible winter temperature at Arctic land stations is calculated to be between $-63^{\circ} \mathrm{C}$. and $-75^{\circ} \mathrm{C}$., the former being the more probable; the lowest recorded temperature is $-69 \cdot 8^{\circ} \mathrm{C}$. at Werchojansk in February 1892. By using the value of the 'eddy diffusivity' found from the kite and 
balloon observations, similar calculations are extended to conditions during the summer and in winds. This discussion of the heat balance is of particular value for a large number of meteorological problems.

During the latter part of the expedition, entirely new methods of observing amounts of precipitation and the formation of hoar frost were devised and successfully used; but lack of space forbids further reference to the fascinating results obtained. This short article must be closed by a reference to the last chapter in the work, entitled "The Circulation of the Air". For the first time the new ideas of the Bergen school of meteorologists have been applied to the interior of the polar regions. Depressions with their characteristic 'fronts' are recognised and their motion determined in so far as that is possible without synoptic charts. There appear to be two main permanent 'fronts' in the Arctic on which depressions form in the winter months-one in north-west Siberia, near to the Bering Straits, and the other between Spitsbergen and Norway. During the winter months the pressure distribution over the Arctic is found to be mainly anticyclonic, but the anticyclonic conditions are frequently destroyed by deep cyclones which form on these two fronts and progress eastwards and northwards into the centre of the polar basin. In the summer the general weather situation is of a more cyclonic character, but the actual disturbances are small and weak compared with the deep winter cyclones.

\section{Development of the Modern Broadcast Receiving Valve}

$\mathrm{T}$ HE specification of most modern broadcasting receivers contains an imposing list of titles describing the various thermionic valves employed in the set. The simple terms, 'high-frequency amplifying', 'detector' and 'low-frequency amplifying', are now no longer sufficient to describe the type of valve and its function in a wireless receiver ; and one is led to speculate whether those investigators who were responsible for the introduction of the terms 'diode' and 'triode,' about sixteen years ago, envisaged the possibility of the octode as a manufacturing proposition in 1934. In the presence of such attainments, it is useful to review the developments which have led to such a complicated valve. Such a review, with special reference to the technique of the manufacture of receiving valves on a mass-production basis, was made by $\mathrm{Mr}$. S. R. Mullard in his chairman's address to the Wireless Section of the Institution of Electrical Engineers on November 7 last.

The thermionic valve, in both the two- and three-electrode forms, was in existence prior to 1914, and its early development was considerably accelerated by the demands of wireless communication during the War period. After this period, the main receiving valve available in Great Britain was the then well-known $R$ type, comprising a cylindrical anode, spiral grid and a co-axial filament of pure tungsten. This valve was available for general purposes as a high- and low-frequency amplifier, a detector or as an oscillation generator. Judged by present-day standards, the valve was very inefficient and, incidentally, rather expensive. Its chief extravagance, as a valve to be used almost universally with batteries, was its filament, the function of which was to produce an electron emission of one or two milliamperes. The main improvements in this direction were the intro- duction in turn of the thoriated tungsten filament and the oxide-coated filament, which is in use in most modern receiving valves; the more recent development of the mains-operated valve has involved the necessity for electrically insulating the heater from the metal cathode carrying the oxide coating. The use of a heated wire coated with oxides of one or more alkaline earths, such as barium and strontium, is reminiscent of the early work on thermionic emission carried out by Elster and Geitel about fifty years ago.

Having placed the cathode in a fairly satisfactory position as an efficient source of electron emission, the valve designer has had to turn his attention to the provision of more than one grid and one anode in order to meet the requirements in the progress of receiving circuit technique. By means of lantern slides, Mr. Mullard illustrated the constructional development of the valve up to the octode of quite recent production. The desirability of keeping the overall size of the receiving valve approximately constant has necessitated the attainment of considerable precision in the dimensions and spacings of the electrode system, and the valve has therefore become, very largely, a machine-made article.

The purpose of the introduction of the additional electrodes into the triode, and the functions fulfilled by the various types of modern receiving valves, are usefully described by A. L. M. Sowerby in a series of four articles in recent numbers of the Wireless World (September 21 and 28, October 12 and November 2). In the first place, the attainable amplification from a three-electrode valve, when used at radio frequencies, is limited by the coupling between the input and output circuits effected through the capacitance between the grid and anode. This difficulty was overcome by the intro- 